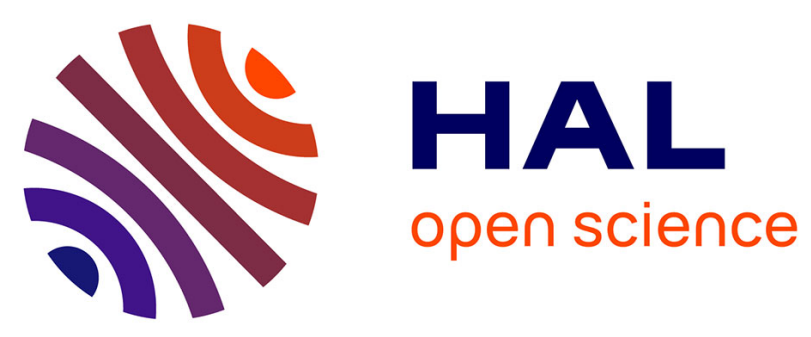

\title{
A Simple Approach to Patterned Protein Immobilization on Silicon via Electrografting from Diazonium Salt Solutions
}

Benjamin S Flavel, Andrew Gross, David J Garrett, Volker Nock, Alison J Downard

\section{To cite this version:}

Benjamin S Flavel, Andrew Gross, David J Garrett, Volker Nock, Alison J Downard. A Simple Approach to Patterned Protein Immobilization on Silicon via Electrografting from Diazonium Salt Solutions. ACS Applied Materials \& Interfaces, 2010, 2 (4), pp.1184-1190. 10.1021/am100020a . hal-03016879

\section{HAL Id: hal-03016879 \\ https://hal.science/hal-03016879}

Submitted on 20 Nov 2020

HAL is a multi-disciplinary open access archive for the deposit and dissemination of scientific research documents, whether they are published or not. The documents may come from teaching and research institutions in France or abroad, or from public or private research centers.
L'archive ouverte pluridisciplinaire HAL, est destinée au dépôt et à la diffusion de documents scientifiques de niveau recherche, publiés ou non, émanant des établissements d'enseignement et de recherche français ou étrangers, des laboratoires publics ou privés. 


\title{
A Simple Approach to Patterned Protein Immobilization on Silicon via Electrografting from Diazonium Salt Solutions
}

\author{
Benjamin S. Flavel, ${ }^{*}$, , Andrew J. Gross, ${ }^{\dagger, \S}$ David J. Garrett, ${ }^{\dagger, \S}$ Volker Nock, ${ }^{\dagger, l}$ and \\ Alison J. Downard*,†,§
}

Department of Chemistry and Department of Electrical \& Computer Engineering, University of Canterbury, Private Bag 4800, Christchurch 8140, New Zealand, and MacDiarmid Institute for Advanced Materials and Nanotechnology, Private Bag 4800, Christchurch 8140, New Zealand

\begin{abstract}
A highly versatile method utilizing diazonium salt chemistry has been developed for the fabrication of protein arrays. Conventional ultraviolet mask lithography was used to pattern micrometer sized regions into a commercial photoresist on a highly doped p-type silicon (100) substrate. These patterned regions were used as a template for the electrochemical grafting of the in situ generated $p$-aminobenzenediazonium cation to form patterns of aminophenyl film on silicon. Immobilization of biomolecules was demonstrated by coupling biotin to the aminophenyl regions followed by reaction with fluorescently labeled avidin and visualization with fluorescence microscopy. This simple patterning strategy is promising for future application in biosensor devices.

KEYWORDS: $p$-phenylenediamine $\bullet$ electrochemical $\bullet$ biotin $\bullet$ avidin $\bullet$ pattern
\end{abstract}

\section{INTRODUCTION}

$\tau$ $n$ recent years, there has been considerable interest in the fabrication of patterned arrays of biological species such as cells $(1,2)$, proteins $(3,4)$, and DNA $(5,6)$ on solid surfaces $(4,7)$. These arrays have potential applications in molecular electronics $(7,8)$, biofuel cells (1), tissue engineering (9), and biosensors and biochips (10). Such future devices will exploit the ability of surface bound receptors to selectively bind target analytes from a complex mixture of other species $(4,9)$. Preparation of patterned surfaces for these purposes typically involves the use of a self-assembled monolayer and conventional lithographic techniques such as microcontact printing $(2,11)$, selective photochemical activation $(7,8,12)$, and photo and electron beam lithography with resists $(10,13-16)$. The goal is usually to fabricate areas of defined shape and size that support or resist immobilization of biological species (17).

A variety of different substrates including silicon $(1,4,8,12,15,17)$, carbon $(18,19)$, glass (7), quartz (20), gallium nitride (21), gold $(2,6,17,22,23)$, and polymers such as poly(dimethylsiloxane) (24-26), polyimide (14), poly(methyl methacrylate) $(11,27,28)$, and polycarbonate $(20,29)$ have been functionalized for biomolecule and cell immobilization. However, for device fabrication, silicon is

* Corresponding author. E-mail: ben.flavel@flinders.edu.au (B.F.);

alison.downard@canterbury.ac.nz (A.J.D.)

Received for review January 10, 2010 and accepted March 04, 2010

${ }^{\dagger}$ Department of Chemistry, University of Canterbury.

* Present address: School of Chemistry, Physics \& Earth Sciences Flinders University, Sturt Road, Bedford Park, Adelaide, South Australia 5001

$\S$ MacDiarmid Institute for Advanced Materials and Nanotechnology.

" Department of Electrical \& Computer Engineering, University of Canterbury.

DOI: $10.1021 / \mathrm{am} 100020 \mathrm{a}$

( ) XXXX American Chemical Society most attractive because an active surface constructed on silicon has the potential to be combined with integrated circuit technology.

The most straightforward approaches to modification of silicon surfaces are those that do not require the removal of the native surface oxide and do not require use of rigorously dry and air-free conditions. Silane chemistry is most commonly used to modify silicon bearing its native oxide layer $(8,9,12,13,15,28,30)$ because of the simplicity of homogeneous layer formation and well-established patterning protocols (31-34). Recently, diazonium cation chemistry has also been shown to offer a route to modification of silicon surfaces, without the need to first remove the native oxide layer (35). Electroreduction of aryldiazonium cations generates, after elimination of dinitrogen, aryl radicals capable of covalent grafting at the electrode surface. Charlier et al. (35) demonstrated that at n-type silicon (100), electroreduction of 4-nitrobenzene-diazonium cation gave strongly adherent films. Under the conditions used in their study, the films were more than $15 \mathrm{~nm}$ thick, consistent with a multilayer structure. The utility of these surfaces for applications in biological media have not yet been investigated.

Currently, there are a limited number of examples of patterned organic layers prepared by the electrochemical reduction of diazonium salts and to our knowledge only two examples on a silicon substrate. In one example, Charlier et al. (35) used ionic implantation to create locally doped silicon surfaces to selectively control the electrografting of 4-nitrobenzenediazonium tetrafluoroborate. In the second example, the same researchers (36) illuminated p-type silicon through a mask, to locally increase the substrate conductivity and allow electrografting of 4-nitrophenyl films. On other surfaces, Ghorbal et al. (37) have used scanning 

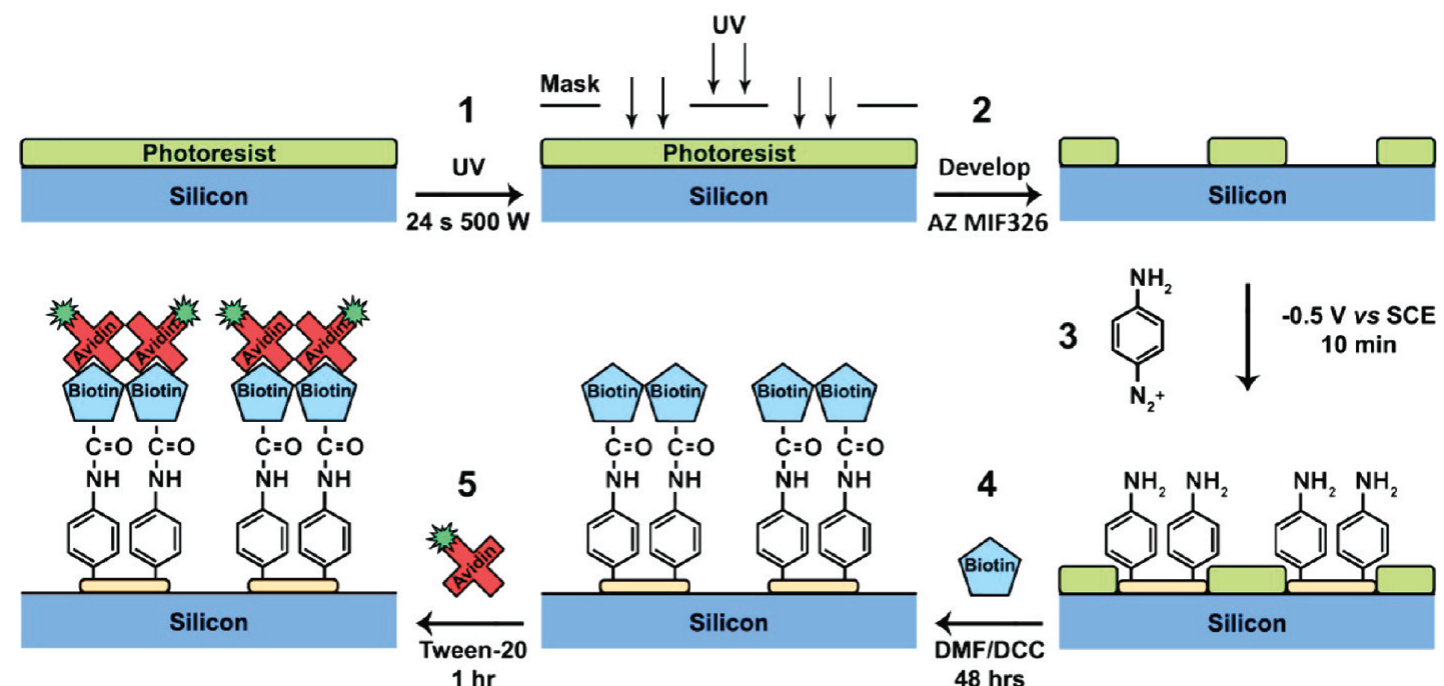

electrochemical microscopy to electrograft nanometre wide lines of vinylic monomers onto a gold substrate. In earlier work, we used mechanical scribing with an atomic force microscope probe to remove regions of electrografted film on a carbon substrate. A second aryldiazonium salt was then electrochemically grafted to the bare regions creating a surface with dual chemical functionality (38). In a different, soft lithographic approach, we patterned a carbon substrate by adhering a poly(dimethylsiloxane) mold to the surface to form micro fluidic channels. The channels were subsequently filled with diazonium salt solution for site specific electrochemical grafting (39). Finally, despite not being an electrochemical method, it is worth mentioning that we have also utilized the spontaneous reduction of aryldiazonium salts on carbon to pattern via microcontact printing with poly(dimethylsiloxane) stamps (40).

The patterning techniques described above all have specific advantages and limitations and there remains a need for additional methods that can quickly and reproducibly fabricate large areas of micrometer-sized patterns of covalently attached films, without restriction on the pattern design. Here we describe the use of conventional photolithography to pattern commercial photoresist onto a silicon surface followed by electrochemical grafting of $p$-aminobenzenediazonium cations to the exposed silicon affording, after removal of the photoresist, a patterned aminophenyl film. To demonstrate the potential application of these patterned surfaces for biomolecule immobilization, we used a condensation reaction to immobilize biotin. This allowed for the subsequent biomolecular recognition reaction with the fluorescently labeled protein avidin, which was imaged with fluorescence microscopy.

\section{EXPERIMENTAL SECTION}

Milli-Q water (MillQ Plus, Millipore, USA) with resistivity $\geq 18$ $\mathrm{M} \Omega \mathrm{cm}$, was used for aqueous solutions and cleaning. Citrate capped colloidal gold nanoparticles were prepared using the method outlined by Chen et al. (41) and Dong et al. (42).

The procedure for fabrication of patterned aminophenyl layers on silicon and subsequent attachment of biotin and avidin is shown schematically in figure 1 . First, highly boron doped p-type silicon (100) with resistivity $<0.001 \Omega \mathrm{cm}$ (Virginia Semiconductor, Inc.) was cut into $2 \mathrm{~cm} \times 2 \mathrm{~cm}$ sized wafers and cleaned by ultrasonication (Elmasonic S 30H, Elma Hans Schmidbauer GmbH \& Co KG, Germany) in $99.5 \%$ acetone (Mallinckrodt Chemicals) for 5 min followed by 5 min in $99.5 \%$ isopropyl alcohol (Sigma-Aldrich) with thorough drying with nitrogen between each solvent. Any remaining surface contamination was removed using an Emitech K1050X plasma asher (Emitech, UK) operating at $100 \mathrm{~W}$ RF power in high purity oxygen (BOC Limited, Australia) for a period of $10 \mathrm{~min}$. Immediately after cleaning, positive tone photoresist AZ1518 (Microchemicals, Germany) was spin-coated to a thickness of $\sim 2 \mu \mathrm{m}$ at $3000 \mathrm{rpm}$ for $30 \mathrm{~s}$ on a PWM32-PS-R790 spinner system (Headway Research Inc., USA) and soft baked for $60 \mathrm{~s}$ at $100{ }^{\circ} \mathrm{C}$ on a standard hot plate. A MA6 mask aligner (Suess Microtec, Germany) operating in vacuum-mode was used to pattern the photoresist by a $24 \mathrm{~s}$ exposure to a $350 \mathrm{~W}$ ultraviolet lamp through chrome on glass masks. After exposure, the photoresist was developed by immersion in AZ MIF326 developer (Microchemicals, Germany) for $25 \mathrm{~s}$, rinsed with water, and dried with nitrogen.

Patterned silicon substrates were used for the electrochemical grafting of aminophenyl films from the corresponding diazonium salt, prepared in situ as described by Lyskawa et al. (43) In brief, $3 \mathrm{~mL}$ of $20 \mathrm{mM}$ p-phenylenediamine (Sigma-Aldrich) in $1 \mathrm{M}$ hydrochloric acid (Sigma-Aldrich) was added to an equal volume of 20 mM $99 \%$ sodium nitrite (Sharlau Chemie, Spain) at room temperature to yield the $p$-aminobenzenediazonium cation. Aminophenyl films were grafted to the silicon substrate by applying a potential of $-0.5 \mathrm{~V}$ vs SCE for $10 \mathrm{~min}$. Immediately after grafting, the silicon substrate was ultrasonicated in Milli-Q water, acetone and isopropyl alcohol for 5, 15, and 5 min respectively. This treatment removed any loosely bound film material and also the surrounding photoresist layer leaving the silicon substrate patterned with aminophenyl groups.

To couple biotin to the patterned aminophenyl film, the substrate was immersed in $10 \mathrm{~mL}$ of degassed $99.9 \% \mathrm{~N}, \mathrm{~N}$ dimethylformamide (DMF) (Southern Cross Scientific Pty. Ltd.) containing $0.01 \mathrm{M}$ D-biotin and $5 \mathrm{mg}$ of $99.0 \% \mathrm{~N}, \mathrm{~N}^{\prime}$-dicyclohexylcarbodiimide (DCC) (Merck, Germany). After incubation for $24 \mathrm{~h}$ under nitrogen, the substrate was rinsed with copious amounts of $\mathrm{N}, \mathrm{N}$-dimethylformamide and water before being ultrasonicated for $5 \mathrm{~min}$ in $0.5 \%$ Tween-20 (Sigma-Aldrich), rinsed with water and dried with nitrogen. This procedure was repeated twice, giving a total incubation time of $48 \mathrm{~h}$. Following immobilization of biotin, the samples were incubated in 0.25 


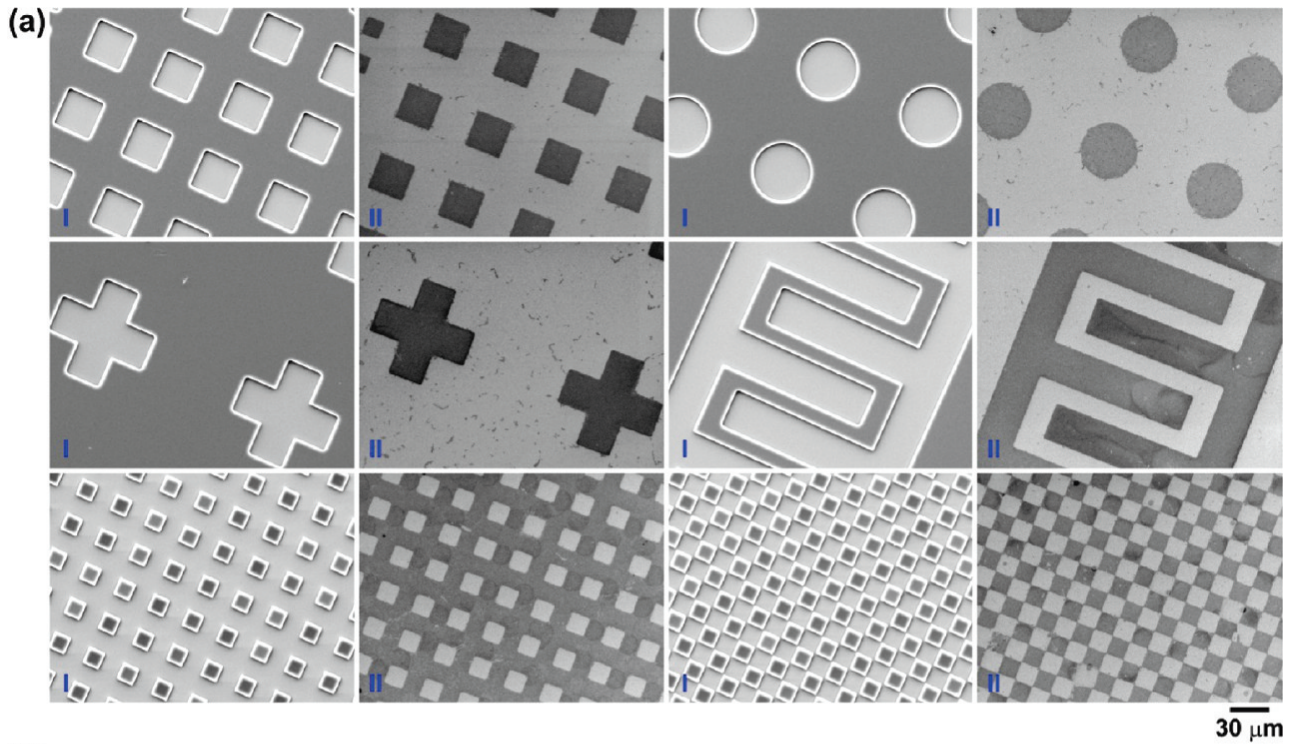

(b)
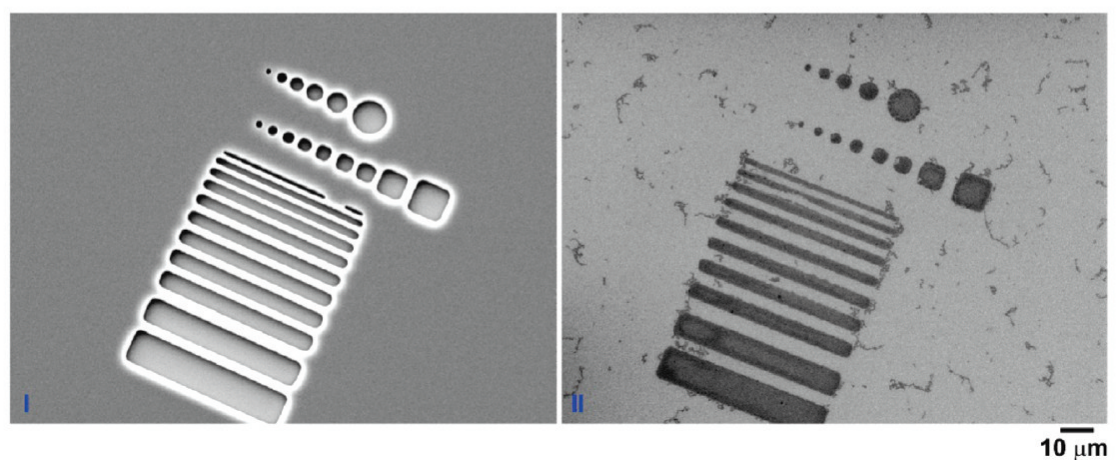

FIGURE 2. SEM images of (I) patterned photoresist and (II) aminophenyl films after electrografting and removal of photoresist for (a) various geometric shapes and (b) a resolution test pattern.

$\mathrm{mg} \mathrm{mL} \mathrm{mL}^{-1}$ of $80 \%$ lyophilized avidin fluorescein isothiocyanate (Sigma-Aldrich) in $0.5 \%$ Tween-20 for $1 \mathrm{~h}$, at room temperature in the dark. Samples were rinsed with $0.5 \%$ Tween-20, dried with nitrogen, and stored in the dark for no longer than $1 \mathrm{~h}$ prior to microscopic analysis.

Electrochemistry. Electrochemical grafting and analyses were performed with an Autolab PGSTAT3C2 Potentiostat/ Galvanostat (Eco Chemie B.V., The Netherlands). Silicon substrates were mounted in a glass electrochemical cell that exposed a circular area of surface to the cell solution as described previously (44). A Viton O-ring defined the geometric area of the working electrode $\left(0.94 \mathrm{~cm}^{2}\right)$. A copper foil on the underside of the silicon substrate provided electrical connection to the working electrode; a platinum wire and saturated calomel electrode (SCE) were used as counter and reference electrodes, respectively

Microscopy. Atomic force microscope (AFM) images were taken in air with a Dimension 3100 and Nanoscope IIIa controller (Digital Instruments, Veeco, USA). Silicon cantilevers (TAP300Al-G series, Budget Sensors, Innovative Solutions Bulgaria Ltd.) with a fundamental resonance frequency of $200-400 \mathrm{kHz}$ were used in tapping mode. Topographic (height) images were obtained at a scan rate of $0.5 \mathrm{~Hz}$ with the parameters set point, amplitude, scan size, and feedback control optimized for each sample. All images presented are background subtracted data using the flatten feature in the Digital Instruments software.

Fluorescence microscopy was undertaken using an Eclipse $80 i$ microscope equipped with a D-FL universal epi-fluorescence attachment and a $100 \mathrm{~W}$ mercury lamp (Nikon Instruments, Japan). Samples were focused using LU Plan Fluor BD objectives (50x, 20x and 10x) (Nikon Instruments, Japan) and passed through an FITC filter block (465 - $495 \mathrm{~nm}$ excitation filter, 505 $\mathrm{nm}$ dichroic, 515-555 BA emission filter). Fluorescence images were captured under darkened conditions by a DS-5Mc-U1 cooled CCD camera and recorded with the NIS-elements v3.07 (Nikon Instruments, Japan) software.

Scanning electron microscope (SEM) images were obtained using a 7000 HRSEM (JEOL, Japan) with an accelerating voltage of $15 \mathrm{kV}$. For the patterned photoresist films on silicon a thin layer of gold and palladium was sputter deposited onto the substrate with an E5000 SEM coating unit (Quorum Technologies, Ringmer, UK).

\section{RESULTS \& DISCUSSION}

Figure 2a, I shows SEM images of the AZ1518 photoresist on silicon after patterning by ultraviolet light exposure for $24 \mathrm{~s}$ through fabricated chrome on glass masks. A series of simple geometric shapes with dimensions as low as $15 \mu \mathrm{m}$ were patterned into the photoresist. Each shape was patterned multiple times with increasing dimensions up to a maximum of $120 \mu \mathrm{m}$. For each pattern the corresponding image after electrografting of an aminophenyl film and removal of photoresist is shown in Figure 2a, II. In these SEM images, regions patterned by aminophenyl film appear dark compared to the surrounding silicon. This is most likely due to the long electrografting time producing a relatively insulating film $(43,45-48)$. To determine the maximum attainable resolution with this technique, we patterned a resolution test into the photoresist as shown in Figure 2b, I. A series of 


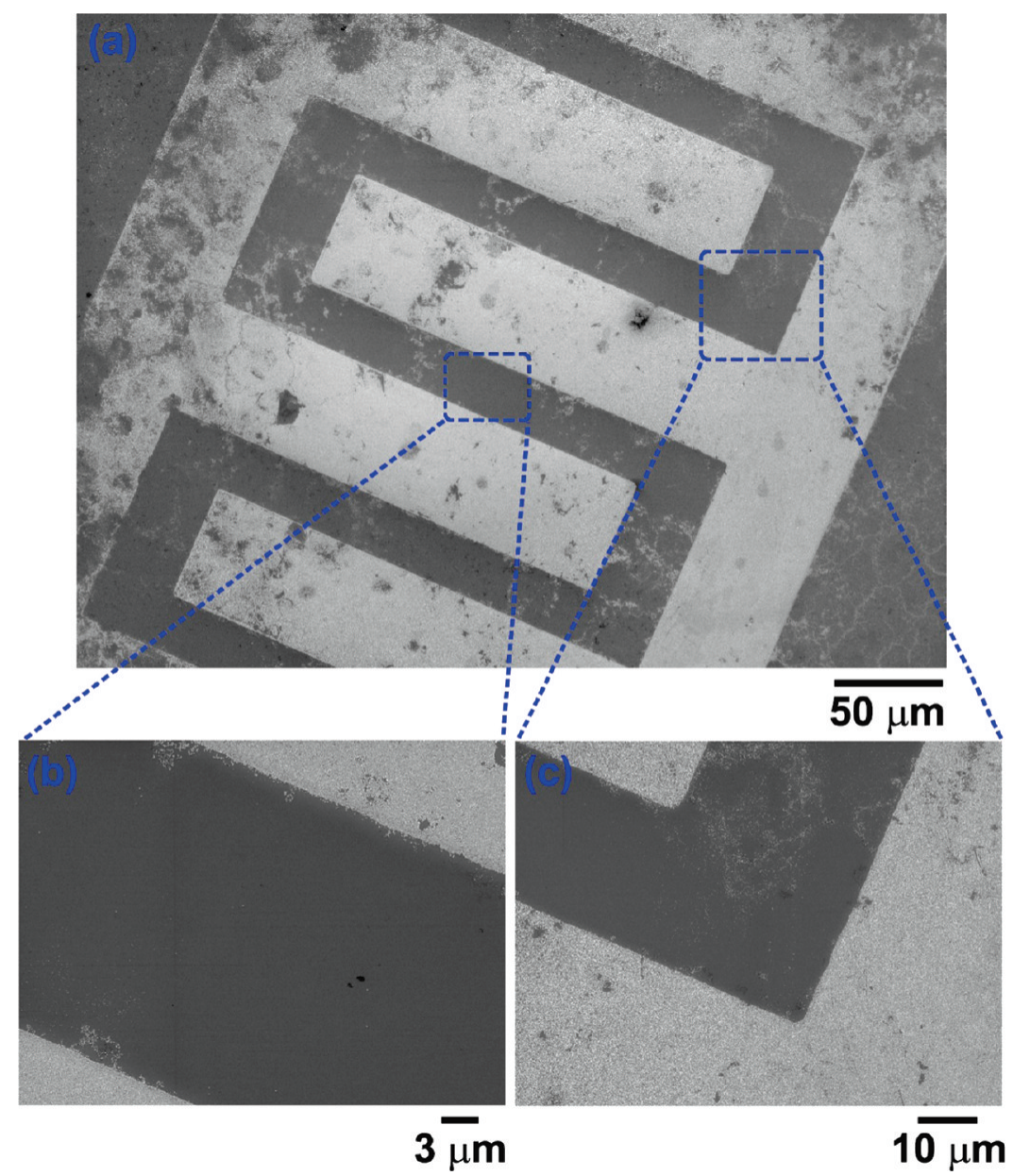

FIGURE 3. SEM images of citrate-capped gold nanoparticles immobilized on (a) a patterned aminophenyl film with (b, c) magnified regions to highlight the highly defined nature of the pattern.

lines, squares, and circles from 10 to $1 \mu \mathrm{m}$ were patterned. Increments of $1 \mu \mathrm{m}$ in width were used for the lines and squares, and circle diameters of $1,2,4,8$, and $10 \mu \mathrm{m}$ were used. For each shape, a $500 \mathrm{~nm}$ feature was also fabricated; however, photoresist exposure and development issues led to poorly defined features, which is particularly evident in the case of the $500 \mathrm{~nm}$ line in Figure 2b, I.

Upon aminophenyl film deposition and photoresist removal, Figure 2 b, II, it can be seen that all structures from 10 to $1 \mu \mathrm{m}$ can be resolved; however, none of the $500 \mathrm{~nm}$ structures are evident. This is assumed to be due to incomplete removal of the photoresist during patterning, which would prevent contact between the solution and the underlying silicon substrate during electrografting. It can also be seen in Figure $2 \mathrm{~b}$, II that in the case of sub- $4 \mu \mathrm{m}$ squares and circles, the dimensions of the aminophenyl features appear smaller than the corresponding photoresist feature. Tapering of the edges of the photoresist that define the feature during photoresist development is the likely origin of this effect.

The maximum lateral resolution, which is easily reproducible with this technique using the equipment in our laboratory is between 1 and $4 \mu \mathrm{m}$. This is comparable to the $1 \mathrm{~m}$ line widths achieved by Charlier et al. (35) utilizing local silicon doping as a promoter of patterned electrograft- ing of diazonium salts. However, unlike that work, the technique presented here is applicable to a wide range of surfaces, not solely materials suitable for patterned doping. It is anticipated that this approach can be applied to graphitic carbons, metals, semiconductors, and even insulating materials (such as Teflon and glass) $(49,50)$. Although aryldiazonium salt-derived films have been patterned to significantly higher lateral resolutions, utilizing an atomic force microscope cantilever tip $(37,38)$ that approach is limited by the slow serial nature of atomic force microscope lithography $(15,33)$.

To verify the presence of amine functionality on the modified surface, the patterned electrografted films were immersed in gold nanoparticle solution $(\mathrm{pH} \sim 5)$ for $40 \mathrm{~min}$. The SEM image in Figure 3a shows gold nanoparticles (lighter regions) self-assembled onto the aminophenyl film modified areas. The self-assembly of gold nanoparticles onto amine terminated layers has been observed many times in the past and is driven by the electrostatic attraction between the negatively charged, citrate-capped, gold nanoparticles and the partially protonated amine layer ( $\mathrm{pKa} \sim 7.5)(51-54)$. These results thus confirm the presence of the amine functionality. It can also be seen in the enlarged images b and $c$ that the edges of the aminophenyl pattern are welldefined. 

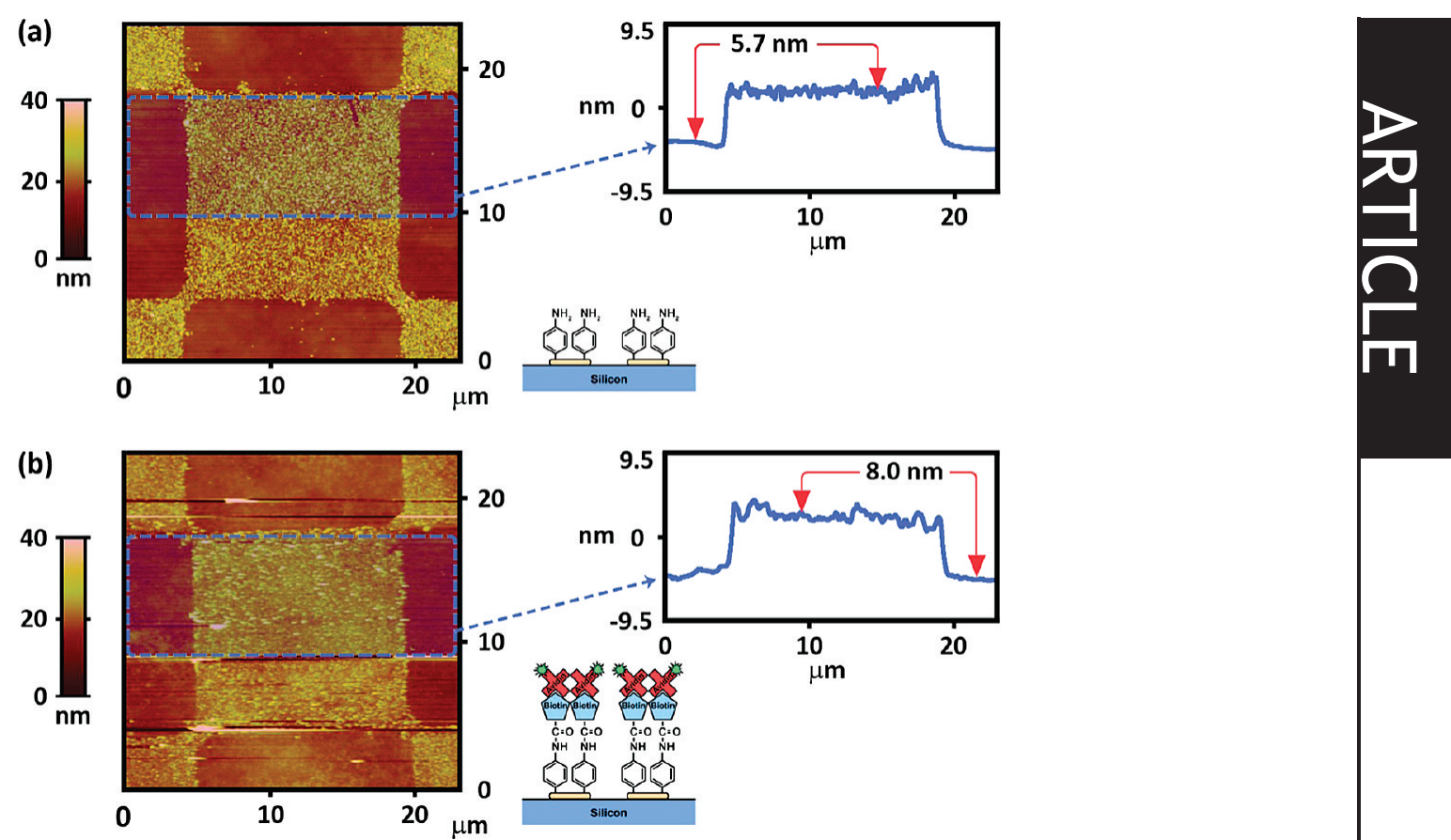

FIGURE 4. AFM image of a $15 \mu \mathrm{m}$ "checkerboard" pattern (a) before and (b) after coupling with biotin and avidin fluorescein isothiocyanate and corresponding average line profiles.

Further investigation of the patterned surface by atomic force microscopy, as shown in figure 4 (a), reveals the unmodified silicon surface is clean, indicating complete removal of the photoresist material. The electrografted film is "grainy" in appearance, consistent with the branching growth (55) of multilayer films that results in a loosely packed structure $(44,56,57)$. Upon taking the average cross section over a $7.5 \times 23 \mu \mathrm{m}$, area as defined by the dashed lines in Figure $4 \mathrm{a}$, the corresponding line profile gives a film thickness of $5.7 \pm 0.2 \mathrm{~nm}$. This is in strong agreement with previous film thickness measurements made using an atomic force tip to remove a section of the film followed by scanning across the film and the scratch to obtain the film thickness. By this method an aminophenyl film, electrografted to silicon under identical conditions to those used here $(-0.5$ $\mathrm{V}$ vs SCE for $10 \mathrm{~min}$ ) was shown to have a thickness of $\sim$ $5.5 \mathrm{~nm}$ (48). (We note that the result obtained here also provides further validitation to the atomic force microscope scratching method as used in many previous experiments for the determination of film thickness (44).)

The same surface shown in Figure 4 a was also imaged with atomic force microscopy after coupling the aminophenyl film with biotin followed by incubation with avidin fluorescein isothiocyanate (Figure $4 \mathrm{~b}$ ). As can be seen by comparison of the line profile graphs, the height of the modified area has now increased by $2.3 \mathrm{~nm}$. This increase confirms the immobilization of biotin and avidin on the aminophenyl film. The egg white avidin molecule has a size of $5 \mathrm{~nm}$ as determined by X-ray diffraction (58-60); however, in air, the size of the molecule is typically smaller than in an aqueous environment due to denaturation (58). Furthermore, in addition to denaturation, it is well-known that because of their softness, most biological samples can easily be deformed or damaged by an atomic force microscope cantilever (61) and this effect may contribute to the measured height of the biotin-avidin layer. Values of between 1.7 and $3 \mathrm{~nm}$ have previously been determined by atomic force microscopy $(58,60)$ and are in agreement with our work.

Fluorescence microscopy was also used to visualize avidin fluorescein isothiocyanate immobilized on the patterned aminophenyl layers. Figure 5 shows the characteristic green fluorescence on a (a) $15 \mu \mathrm{m}$ "checkerboard" pattern (b) 100 $\mu \mathrm{m}$ wide cross, and (c) $60 \mu \mathrm{m}$ diameter circle. Traces of nonspecific binding of avidin were observed on the unmodified silicon areas; however, increased protection against nonspecific adsorption can be afforded by passivating the background silicon with a protein resistant poly(ethylene glycol) silane $(27,62)$, or using a blocking agent such as bovine serum album (BSA). Control samples patterned with aminophenyl film were incubated in avidin fluorescein isothiocyanate without first immobilizing biotin, and as expected, only trace levels of fluorescence was observed within the patterns or the background. Furthermore, an aminophenyl film placed in a biotin/DMF solution in the absence of DCC prior to incubation in avidin fluorescein isothiocyanate showed little fluorescence, demonstrating that covalent attachment is a prerequisite for biotin immobilization. These observations, consistent with selective interaction of avidin and, by inference, biotin, at the modified silicon surface confirm that biotin can be covalently coupled to the aminophenyl film and subsequently form a complex with avidin. This provides a simple and straightforward method for patterned immobilization of proteins via complexation of biotin-labeled proteins with immobilized avidin. 

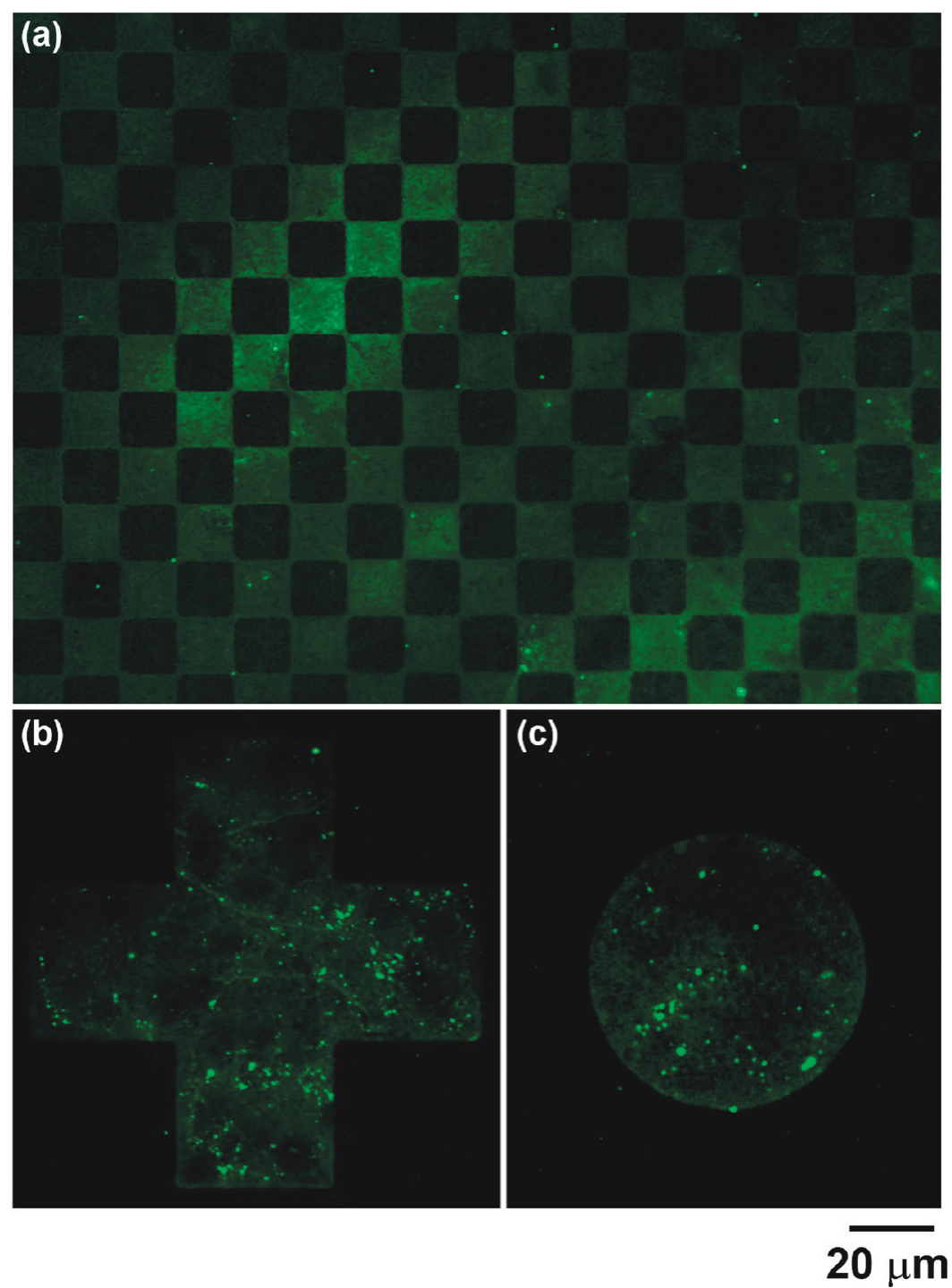

FIGURE 5. Fluorescence microscopy image of avidin fluorescein isothiocyanate immobilized on (a) $15 \mu \mathrm{m}$ "checkerboard" pattern, (b) 100 $\mu \mathrm{m}$ wide cross, and (c) $60 \mu \mathrm{m}$ diameter circle.

\section{CONCLUSION}

This work has demonstrated a simple, convenient photolithographic method for patterning silicon with electrografted aminophenyl films. Attractive features of the method are that removal of the native oxide layer is not necessary prior to grafting and the method is suitable for rapid patterning of large surface areas. Use of diazonium salts for grafting gives films that are sufficiently stable to withstand the cleaning steps necessary for removal of photoresist. It is anticipated that this method can be extended to many different substrates and a variety of aryldiazonium salts. Patterns with lateral features down to $1 \mu \mathrm{m}$ were achieved, however, with the use of electron beam lithographic techniques, lower dimensions should be possible. To demonstrate the potential application of patterned substrates in biosensing devices, biotin was covalently coupled to the patterned aminophenyl film to facilitate the immobilization of the protein avidin. Atomic force and fluorescence microscopy confirmed the selective immobilization of avidin on the aminophenyl film. In work currently under way, we are investigating preparation of patterned aminophenyl films that are amenable to electrochemical as well as fluorescence detection methods.

Acknowledgment. This work was funded by the MacDiarmid Institute for Advanced Materials and Nanotechnology. B.S.F. thanks the Australian Government's Endeavour Research Fellowship program; A.J.G. thanks the MacDiarmid Institute for a Doctoral Scholarship, and D.J.G. thanks the Tertiary Education Commission for a Bright Futures Top Achiever Doctoral Scholarship. We thank Helen Devereux for technical assistance.

\section{REFERENCES AND NOTES}

(1) Bearinger, J. P.; Dugan, L. C.; Wu, L.; Hill, H. A.; Christian, T.; Hubbell, J. A. BioTechniques 2009, 46, 209.

(2) Mrksich, M.; Dike, L. E.; Tien, J.; Ingber, D. E.; Whitesides, G. M. Exp. Cell Res. 1997, 235, 305.

(3) Blawas, A. S.; Reichert, W. M. Biomaterials 1998, 19, 595.

(4) Lee, C.-S.; Lee, S.-H.; Park, S.-S.; Kim, Y.-K.; Kim, B.-G Biosens. Bioelectron. 2003, 18, 437.

(5) Demers, L. M.; Ginger, D. S.; Park, S.-J.; Li, Z.; Chung, S.-W.; Mirkin, C. A Science 2002, 296, 1836. 
(6) Smith, E. A.; Wanat, M. J.; Cheng, Y.; Barreira, S. V. P.; Frutos, A. G.; Corn, R. M. Langmuir 2001, 17, 2502

(7) Choi, H. J.; Kim, N. H.; Chung, B. H.; Seong, G. H. Anal. Biochem 2005, 347, 60 .

(8) Koyano, T.; Saito, M.; Miyamoto, Y.; Kaifu, K.; Kato, M. Biotechnol. Prog. 1996, 12, 141

(9) Christman, K. L.; Enriquez-Rios, V. D.; Maynard, H. D. Soft Matter 2006, 2, 928

(10) Bashir, R.; Gomez, R.; Sarikaya, A.; Ladisch, M. R.; Sturgis, J.; Robinson, J. P. Biotechnol. Bioeng. 2001, 73, 324

(11) Schmalenberg, K. E.; Buettner, H. M.; Uhrich, K. E. Biomaterials 2004, 25, 1851

(12) Orth, R. N.; Clark, T. G.; Craighead, H. G. Biomed. Microdev. 2003, 5, 29.

(13) Harnett, C. K.; Satyalakshmi, K. M.; Craighead, H. G. Langmuir 2001, 17, 178 .

(14) Schwarz, A.; Rossier, J. S.; Roulet, E.; Mermod, N.; Roberts, M. A.; Girault, H. H. Langmuir 1998, 14, 5526.

(15) Zhang, G.-J.; Tanii, T.; Zako, T.; Hosaka, T.; Miyake, T.; Kanari, Y.; Funatsu, T.; Ohdomari, I Small 2005, 1, 833.

(16) Mooney, J. F.; Hunt, A. J.; McIntosh, J. R.; Liberko, C. A.; Walba, D. M.; Rogers, C. T Proc. Natl. Acad. Sci. U.S.A. 1996, 93, 12287

(17) Veiseh, M.; Zareie, M. H.; Zhang, M. Langmuir 2002, 18, 6671

(18) Chenghong, L.; Jiaqi, D. Anal. Chem. 1996, 68, 3344

(19) Kong, Y.-T.; Boopathi, M.; Shim, Y.-B Biosens. Bioelectron. 2003, 19,227

(20) Brooks, S. A.; Dontha, N.; Brandon Davis, C.; Stuart, J. K.; O’Neill, G.; Kuhr, W. G. Anal. Chem. 2000, 72, 3253

(21) Baur, B.; Steinhoff, G.; Hernando, J.; Purrucker, O.; Tanaka, M. Nickel, B.; Stutzmann, M.; Eickhoff, M. Appl. Phys. Lett. 2005, 87, 263901

(22) Ignatov, S.; Shishniashvili, D.; Ge, B.; Scheller, F. W.; Lisdat, F Biosens. Bioelectron. 2002, 17, 191

(23) Brockman, J. M.; Frutos, A. G.; Corn, R. M. J. Am. Chem. Soc. 1999 $121,8044$.

(24) De Silva, M. N.; Desali, R.; Odde, D. J. Biomed. Microdev. 2004, 6, 219.

(25) Nishikawa, M.; Yamamoto, T.; Kojima, N.; Kikuo, K.; Fujii, T.; Sakai, Y. Biotechnol. Bioeng. 2007, 99, 1472

(26) Shamansky, L. M.; Davis, C. B.; Stuart, J. K.; Kuhr, W. G. Talanta 2001, 55, 909.

(27) Christman, K. L.; Requa, M. V.; Enriquez-Rios, V. D.; Ward, S.; Bradley, K. A.; Turner, K. L.; Maynard, H. D. Langmuir 2006, 22, 7444.

(28) Jonkheijm, P.; Weinrich, D.; Schröder, H.; Niemeyer, C. M.; Waldmann, H. Angew. Chem., Int. Ed. 2008, 47, 9618.

(29) Bora, U.; Sharma, P.; Kumar, S.; Kannan, K.; Nahar, P. Talanta 2006, 70,624

(30) Arakaki, A.; Hideshima, S.; Nakagawa, T.; Niwa, D.; Tanaka, T.; Matsunga, T.; Osaka, T. Biotechnol. Bioeng. 2004, 88, 543.

(31) Aswal, D. K.; Lenfant, S.; Guerin, D.; Yakhmi, J. V.; Vuillaume, D. Anal. Chim. Acta , 568, 84
(32) Flavel, B. S.; Yu, J.; Ellis, A. V.; Quinton, J. S.; Shapter, J. G Nanotechnol. 2008, 19, 445301

(33) Flavel, B. S.; Yu, J.; Shapter, J. G.; Quinton, J. S. Carbon 2007, 45, 2551

(34) St. John, P. M.; Craighead, H. G. Appl. Phys. Lett. 1996, 68, 1022

(35) Charlier, J.; Palacin, S.; Leroy, J.; Del Frari, D.; Zagonel, L.; Barrett, N.; Renault, O.; Bailly, A.; Mariolle, D.J. Mater. Chem. 2008, 18, 3136.

(36) Charlier, J.; Clolus, E.; Bureau, C.; Palacin, S.J. Electroanal. Chem. 2009, 625, 97.

(37) Ghorbal, A.; Grisotto, F.; Charlier, J.; Palacin, S.; Goyer, C.; Demaille, C. Chem. Phys. Chem 2009, 10, 1053.

(38) Brooksby, P. A.; Downard, A. J. Langmuir 2005, 21, 1672

(39) Downard, A. J.; Garrett, D. J.; Tan, E. S. Q. Langmuir 2006, 22, 10739.

(40) Garrett, D. J.; Lehr, J.; Miskelly, G. M.; Downard, A. J.J. Am. Chem. Soc. 2007, 129, 15456

(41) Guan, F.; Chen, M.; Yang, W.; Wang, J.; Yong, S.; Xue, Q. Appl. Surf. Sci. 2005, 240, 24

(42) Jin, Y.; Kang, X.; Song, Y.; Zhang, B.; Cheng, G.; Dong, S. Anal. Chem. 2001, 73, 2843

(43) Lyskawa, J.; Belanger, D. Chem. Mater. 2006, 18, 4755.

(44) Brooksby, P. A.; Downard, A. J. Langmuir 2004, 20, 5038.

(45) D’Amours, M.; Belanger, D.J. Phys. Chem., B 2003, 107, 4811.

(46) Downard, A. J.; Prince, M. J. Langmuir 2001, 17, 5581

(47) Ortiz, B.; Saby, C.; Champagne, G. Y.; Belanger, D. J. Electroanal. Chem. , 455, 75 .

(48) Flavel, B. S.; Garrett, D. J.; Lehr, J.; Shapter, J. G.; Downard, A. J. Electrochimi. Acta 2010, in press

(49) Pinson, J.; Podvorica, F. Chem. Soc. Rev. 2005, 34, 429.

(50) Mevellec, V.; Roussel, S.; Tessier, L.; Chancolon, J.; MayneL'Hermite, M.; Deniau, G.; Viel, P.; Palacin, S. Chem. Mater. 2007, 19,6323

(51) Shipway, A. N.; Katz, E.; Willner, I. Chem. Phys. Chem. 2000, 1, 18 .

(52) Park, J.; Lee, H. Colloids Surf., A 2005, 275, 133.

(53) Shipway, A. N.; Lahav, M.; Willner, I. Adv. Mater. 2000, 12, 993.

(54) Li, O.; Zheng, J.; Liu, Z. Langmuir 2003, 19, 166.

(55) Yu, S. S. C.; Tan, E. S. Q.; Jane, R. T.; Downard, A. J. Langmuir 2007, 23, 11074

(56) Brooksby, P. A.; Downard, A. J.J. Phys. Chem., B 2005, 109, 8791

(57) Paulik, M. G.; Brooksby, P. A.; Abell, A. D.; Downard, A. J.J. Phys Chem., C 2007, 111, 7808

(58) Misawa, N.; Yamamura, S.; Yong-Hoon, K.; Tero, R.; Nonogaki, Y.; Urisu, T. Chem. Phys. Lett. 2006, 419, 86.

(59) Aoki, R.; Arakawa, T.; Misawa, N.; Tero, R.; Urisu, T.; Tekeuchi, A.; Ogino, T. Surf. Sci. 2007, 601, 4915.

(60) Ebner, A.; Hinterdorfer, P.; Gruber, H. J. Ultramicroscopy 2007. 107, 922.

(61) Zhang, Y.; Sheng, S.; Shao, Z Biophys.J. 199671, 2168.

(62) Papra, A.; Bernard, A.; Juncker, D.; Larsen, N. B.; Michel, B.; Delamarche, E. Langmuir 2001, 17, 4090 